\title{
Comparison of Gas Permeability and Selectivity Between Alumina Membrane and Vycor Glass at High Temperatures
}

\author{
F. N. Tüzün, E. Koçdemir, G.Uğuz \\ Department of Chemical Engineering, Hitit University, Çorum, TURKEY \\ Email: nihaltuzun@yahoo.com
}

Received 2012

\begin{abstract}
In this study, gas permeability and selectivity of Vycor glass and alumina membrane were compared by using $\mathrm{H}_{2}, \mathrm{CO}_{2}, \mathrm{CO} \mathrm{CH}_{4}$ and $\mathrm{N}_{2}$ gases at the temperatures of 323-823 K before and afterapplying the silica coating process. $\mathrm{H}_{2}$ permeability decreased with increasing the temperature before silica coating both in Vycor glass and alumina membrane. However, $\mathrm{H}_{2}$ permeability increased with increasing the temperature, that was an indication of activated transport after silica coating both in Vycor glass and alumina membrane. Lower permeability values and higher selectivities were obtained in Vycor glass membrane than alumina membrane having higher permeability and lower selectivities.
\end{abstract}

Keywords: Membrane; Hydrogen; Permeability; Selectivity

\section{Introduction}

Membrane separation of gaseous mixtures has come to attract much attention from the viewpoint of energy-conservative recovery of gases, especially at high temperature, where most of ordinary organic membranes can not be applied because of their thermal instability. In contrast, inorganic membranes, which seem quite stable at high temperature and against most chemicals, will preferably be applied to gas separation processes as in [1].

The preparation and application of ceramic membranes has received much attention in the past few years as in [2]. Ceramic membranes are technically important in separation and filtration as well as in catalytic reactions, because of their high thermal and chemical stability, long life time and good defouling properties in comparison with polymeric membranes as in $[3,4]$.

Hydrogen permeable and selective silica membranes have attracted much interest in the membrane gas separation field due to the importance of hydrogen as an industrial feedstock for the production of fuels and many chemicals as in [5, 6]. Silica membranes are attractive since they are chemically and thermally stable while offering high permeability and selectivity for hydrogen as in [7].

Silica fabricated by the sol-gel process is known to have high surface area and microporosity as in [8-10]. The sol-gel process, in this case, refers to the controlled hydrolysis and polymerization of tetraethylorthosilicate(TEOS) in a water-alcohol solution as in $[11,12]$. The solution goes through an irreversible sol-gel transition. The resulting gel can be dried to a rigid silica-like material.

\section{Experimental}

The alumina membrane changing the particle size distribution

*The scientific and technological research council of turkey gave the financial support for the preparation of this work. from $3 \mu \mathrm{m}$ to $70 \mathrm{~nm}$ with the diameter of $21 \mathrm{~mm}$ and the thickness of $1 \mathrm{~mm}$ was purchased from Germany. The Vycor glass having the mean particle size of 40 Angstrom with the diameter of $21 \mathrm{~mm}$ and the thickness of $1 \mathrm{~mm}$ was purchased from USA. Gas permeability tests of Vycor glass and alumina membrane were performed by using $\mathrm{H}_{2}, \mathrm{CO}_{2}, \mathrm{CO}, \mathrm{N}_{2}$ and $\mathrm{CH}_{4}$ gases at constant volume-variable pressure measurement system between 323 and $823 \mathrm{~K}$ and $\mathrm{H}_{2}$ selectivites over other gases were determined. Then, alumina membrane was dipped into LUDOX colloidal silica solution at 2-3 s, subsequently, it was calcined in the oven up to the temperature of $1173 \mathrm{~K}$ with heating rate of $1 \mathrm{~K} / \mathrm{min}$. After two hours passed at the temperature of $1173 \mathrm{~K}$, calcination was continued with cooling rate of $1 \mathrm{~K} / \mathrm{min}$. However, sol-gel process was applied to Vycor glass by refluxing a solution of TEOS, $\mathrm{H}_{2} \mathrm{O}, \mathrm{C}_{2} \mathrm{H}_{5} \mathrm{OH}$ and $\mathrm{HNO}_{3}$ in the ratio of 1 : 1 : 26: 11.76 respectively at $353 \mathrm{~K}$ for two hours. A sample of solution was diluted with $\mathrm{C}_{2} \mathrm{H}_{5} \mathrm{OH}$ in the ratio of $1: 18$ and membrane was dipped for a few seconds. It was then dried at $393 \mathrm{~K}$ for three hours with heating rate of $1 \mathrm{~K} / \mathrm{min}$ and calcined at $673 \mathrm{~K}$ for three hours with the same heating rate. The dipping was repeated a second time with the dilution being 1:180.

After silica coating processes of Vycor glass and alumina membrane were completed, they were exposed to gas permeation experiments with using $\mathrm{H}_{2}, \mathrm{CO}_{2}, \mathrm{CO}, \mathrm{N}_{2}$ and $\mathrm{CH}_{4}$ gases among 323 and $823 \mathrm{~K}$ and $\mathrm{H}_{2}$ selectivites over other gases were detected.

\section{Results and Discussion}

Gas permeability test of samples including Vycor glass and alumina membrane before and after silica coating was fulfilled by using constant volume-variable pressure measurement system for the temperatures around 323 and $823 \mathrm{~K}$ and $\mathrm{H}_{2}$ selectivites over other gases were determined. Permeability coefficient of each gas was calculated from (1) and selectivity was also detected from (2). 


$$
F=\frac{Q}{A * \Delta P}
$$

Q: flow rate of gas $\left(\mathrm{m}^{3} / \mathrm{s}\right)$

A: membrane crossectional area $\left(\mathrm{m}^{2}\right)$

$\Delta \mathrm{P}$ : pressure difference $(\mathrm{Pa})$

F: permeability coefficient $\left(\mathrm{m}^{3} / \mathrm{m}^{2}\right.$.s.Pa)

$$
\alpha \equiv \frac{\text { Ppermeate }}{\text { Pfeed }}
$$

P: pressure

$\alpha$ : selectivity

Variation of $\mathrm{H}_{2}$ permeability with the temperature for alumina membrane before and after silica coating was given in Figures 1 and 2 respectively.

Variation of $\mathrm{H}_{2}$ permeability with the temperature for Vycor glass before and after silica coating was observed in Figures 3 and $\mathbf{4}$ respectively as well.

As it was observed from Figures 1, 2, 3 and 4, $\mathrm{H}_{2}$ permeability decreased with increasing the temperature before silica coating both in Vycor glass and alumina membrane. However, $\mathrm{H}_{2}$ permeability increased with increasing the temperature, which was a characteristic of activated transport as in [13] after silica coating both in Vycor glass and alumina membrane. Moreover, $\mathrm{H}_{2}$ selectivities over other gases for both membranes were given in Tables 1 and 2.

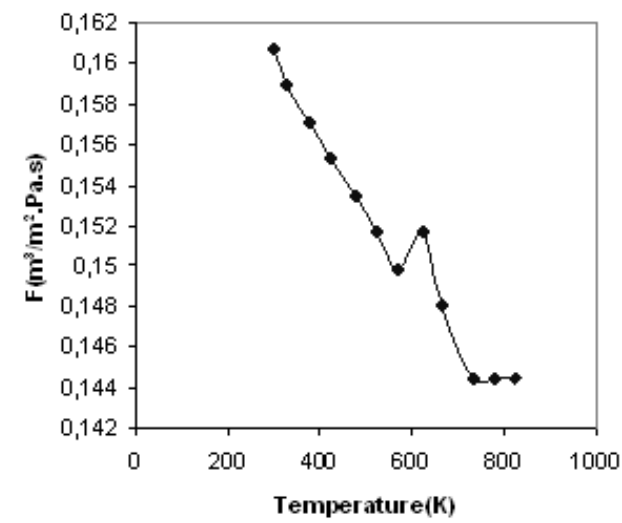

Figure 1. Variation of $\mathrm{H} 2$ permeability with temperature for alumina membrane before silica coating.

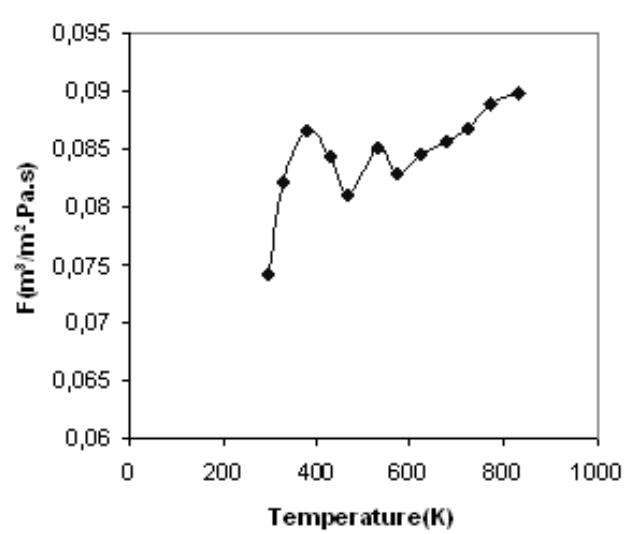

Figure 2. Variation of $\mathbf{H} 2$ permeability with temperature for alumina membrane after silica coating.

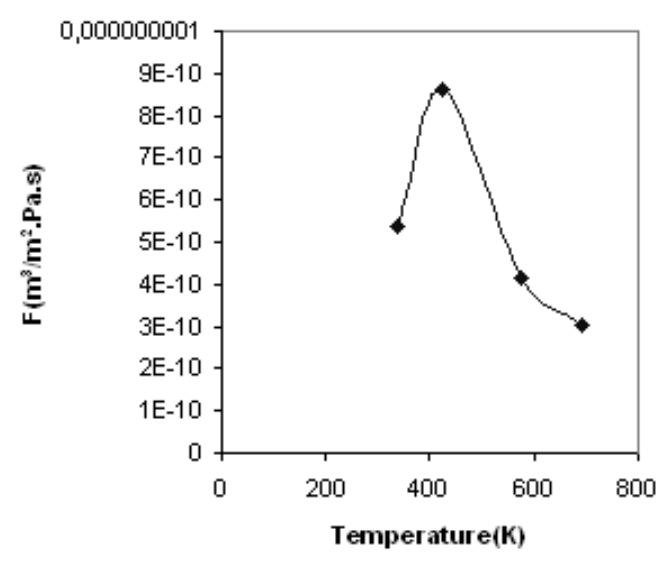

Figure 3. Variation of $\mathbf{H 2}$ permeability with temperature for Vycor glass before silica coating.

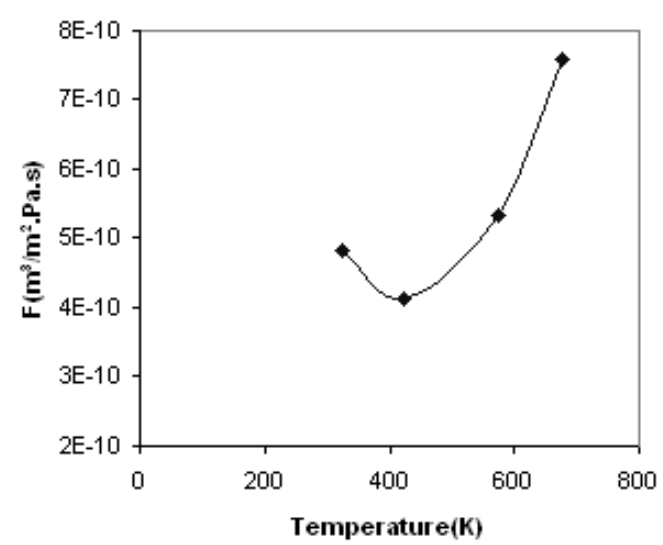

Figure 4. Variation of $\mathbf{H} 2$ permeability with temperature for Vycor glass after silica coating.

Table 1. $\mathrm{H}_{2}$ selectivities over other gases for alumina membrane.

\begin{tabular}{ccc}
\hline \multicolumn{3}{c}{ Alumina membrane } \\
\hline Selectivities & Before silica coating & After silica coating \\
\hline $\mathrm{H}_{2} / \mathrm{N}_{2}$ & 0,221118012 & 0,030482257 \\
$\mathrm{H}_{2} / \mathrm{CO}_{2}$ & 0,148472744 & 1,777078454 \\
$\mathrm{H}_{2} / \mathrm{CH}_{4}$ & 0,15335213 & 0,030238693 \\
\hline
\end{tabular}

Table 2. $\mathbf{H}_{2}$ selectivities over other gases for Vycor glass.

\begin{tabular}{ccc}
\hline \multicolumn{3}{c}{ Vycor glass } \\
\hline Selectivities & Before silica coating & After silica coating \\
\hline $\mathrm{H}_{2} / \mathrm{N}_{2}$ & 6.515 & 4.712 \\
$\mathrm{H}_{2} / \mathrm{CO}_{2}$ & 5.346 & 5.763 \\
$\mathrm{H}_{2} / \mathrm{CH}_{4}$ & 4.475 & 10.468 \\
\hline
\end{tabular}

According to the Tables 1 and $2, \mathrm{H}_{2}$ selectivities over $\mathrm{N}_{2}$ and $\mathrm{CH}_{4}$ gases decreased, while $\mathrm{H}_{2}$ selectivity with respect to $\mathrm{CO}_{2}$ gas increasing after silica coating in alumina membrane. This result may be due to the surface diffusion of gas molecules. However, $\mathrm{H}_{2}$ selectivities over $\mathrm{CO}_{2}$ and $\mathrm{CH}_{4}$ gases increased, when $\mathrm{H}_{2}$ selectivity in view of $\mathrm{CO}_{2}$ gas decreased after silica coating in Vycor glass.

Results showed that alumina membrane with having higher permeability and lower selectivity, Vycor glass membrane having lower permeability and higher selectivity were obtained. 


\section{Acknowledgements}

The authors would like to thank to the scientific and technological research council of turkey for the financial support given in 2209 Scientist Supporting Programme related to the preparation of this work.

\section{REFERENCES}

[1] S.Kitao, H.Kameda, M.Asaeda, Membrane, 15(4), 222-227 (1990).

[2] J.-H.Lee, S.-C. Choi, D.-S.Bae, K.-S. Han, Journal of Materials Science Letters, 18(1999) 1367-1369.

[3] Y.S.Lin, A.J.Burggraaf, J.Amer.Ceram.Soc., 74(1991) 29.

[4] K.K. Chan, A.M. Brownstein, Amer.Ceram.Soc. Bull.70(1991) 703.
[5] R.Ramachandran, R.K.Menon, Int.J.Hydrogen Energy 23(1998) 593.

[6] T.N.Veziroglu, Chem.Ind.53(1999) 383.

[7] A.J.Burggraaf, L.Cot, Fundamentals of Inorganic Membrane Science and Technology, Elsevier, Amsterdam, 1996.

[8] B.E.Yoldas, J.Non-Cryst.Solids 63, 145(1984).

[9] C.J.Brinker, K.D.Keefer, D.W.Schaefer, C.S.Ashley, J.Non-Cryst.Solids 48, 47(1982).

[10] J.Zarzycki, M.Prassas, J.Phalippou, J.Mater.Sci. 17, 3371(1982).

[11] R.Aelion, A.Loebel, F. Eirich, Amer.Ceram.Soc. 72, 5705(1950).

[12] H.Dislich, P. Hinz, J.Non-Cryst.Solids 48, 11(1982).

[13] S.Giessler, L.Jordan, J.C.D.Da Costa, Separation and Purification Technology, 32(2003) 255. 